\title{
Pilot study on university students' opinion about STEM studies at higher education $\left(^{*}\right)$
}

\author{
Sonia Verdugo-Castro \\ GRIAL Research Group, Research Institute for Educational \\ Sciences, University of Salamanca, Salamanca, Spain \\ soniavercas@usal.es \\ Alicia García-Holgado \\ GRIAL Research Group, Research Institute for Educational \\ Sciences, University of Salamanca, Salamanca, Spain \\ aliciagh@usal.es
}

\begin{abstract}
The percentages of women enrolled in higher education in the STEM sector are significantly lower than those of men. Overall, gender representation in science, technology, engineering and mathematics degrees in Europe is not balanced. The Leaky Pipeline phenomenon, marked by gender stereotypes, makes the latent gender gap a relevant topic of study. Studies exist on academic performance, self-perception, self-efficacy, outcome expectations; however, studying gender stereotypes linked to STEM studies is also essential. It is necessary to know the social and family context in which young people have grown up, as well as their perception of such studies To study gender stereotypes of university students about STEM studies, a questionnaire has been designed for empirical validation For the design of the instrument, to be validated, items from other instruments have been taken and adapted to Spanish. After the design of the instrument, an online pilot study has been applied in the University of Salamanca, the University of Valencia and the Polytechnic University of Valencia. A total of 115 people answered the questionnaire. The results of the pilot study reveal that the study sample is not particularly marked by gender stereotypes about gender equality in STEM. Also, the sample is receptive to learning about science and applying it in their lives. On the other hand, the idea that women have to give up their studies and careers to look after their families and children is rejected. The idea that men are more interested in university studies than women is also rejected. At the same time, the sample is aware of the difficulties that women encounter in the STEM sector. Another optimistic point of the results is that there are no alarming data on bad experiences due to gender. In the future, the study will be replicated on a larger scale.
\end{abstract}

\author{
$M^{\mathrm{a} C}$ Cruz Sánchez Gómez \\ GRIAL Research Group, Research Institute for Educational \\ Sciences, University of Salamanca, Salamanca, Spain \\ mcsago@usal.es \\ Margarita Bakieva \\ GEM-EduCo Research Group, Dept. of Research Methods \\ and Diagnostics in Education, University of Valencia, \\ Valencia, Spain \\ margarita.bakieva@uv.es
}

\section{CCS CONCEPTS}

- Social and professional topics $\rightarrow$ User characteristics; Gender; Women; User characteristics; Age; Adolescents; Professional topics; Computing education; Adult education.

\section{KEYWORDS pipeline, STEM \\ ACM Reference Format:}

Questionnaire, gender stereotypes, gender roles, gender gap, leaky

Sonia Verdugo-Castro, M ${ }^{\mathrm{a}} \mathrm{Cruz}$ Sánchez Gómez, Alicia García-Holgado, and Margarita Bakieva. 2020. Pilot study on university students' opinion about STEM studies at higher education. In Eighth International Conference on Technological Ecosystems for Enhancing Multiculturality (TEEM'20), October 21-23, 2020, Salamanca, Spain. ACM, New York, NY, USA, 8 pages. https://doi.org/10.1145/3434780.3436616

\section{INTRODUCTION}

The gender gap in STEM (acronym of Science, Technology, Engineering and Mathematics) higher education is a reality. According to data published by Eurostat [11], in Spain 248,935 men and 89,525 women enrolled in engineering, manufacturing and construction tertiary studies in 2013, 244,769 men and 86,507 women in 2014, 234,222 men and 81,369 women in 2015, 220,770 men and 76,556 women in 2016, 218,891 men and 74,744 women in 2017 and 213,807 men and 72,377 women in 2018. In Information and Communication Technology degrees in Spain 78,363 men and 13,406 women were enrolled during 2013, 80,804 men and 13,304 women during $2014,79,466$ men and 12,250 women during 2015, 80,526 men and 12,018 women during 2016, 85,291 men and 12,236 women during 2017 and 89,403 men and 12,776 women during 2018. This trend continues in Software Engineering with 24,763 men enrolled and 4,214 women in $2015,26,924$ men and 4,365 women during 2016, 30,880 men and 4,667 women during 2017 and 33,666 men and 5,065 women during 2018 . The trend of perpetuating the disparity without achieving margins of equality continues in other STEM degrees. In Electricity and Energy-related degrees in Spain, 12,878 men and 2,787 women were enrolled in 2018. In Architecture, 28,894 men and 19,822 women were enrolled in 2018. In Physics, 9,945 men and 3,636 women were enrolled in 2018. In Mathematics, 7,572 men and 4,408 women enrolled in 2018 . This difference does not only occur 


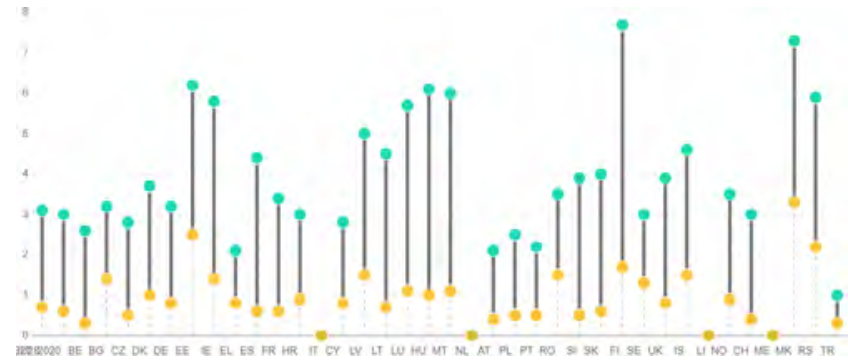

Figure 1: Distribution of students enrolled in tertiary studies in the field of Information and Communication Technologies, by gender in 2018, in Europe. Source: European Institute for Gender Equality [10].

in Spain but is shared by the different countries of Europe [11]. Figure 1 shows the distribution of students enrolled in tertiary studies in the field of Information and Communication Technologies, by sex, in the year 2018, in Europe. Men are represented in blue and women in ochre.

The gender gap is produced by horizontal segregation, which results in occupational segregation [16, 28, 36, 39]. The horizontal segregation means that women have higher percentages of representation in some disciplines than others. There are different factors involved in this educational, labour and social phenomenon, as explained by the Social Cognitive Career Theory (SCCT), defined by Lent, Brown and Hackett (1994) [20]. Some of the main influential factors are self-perception, self-efficacy, interest in science, expectations of results, previous educational experiences, family and social context, personal characteristics of the person and his/her objectives when deciding which studies to take [20].Also, other adaptations have emerged from the Social Cognitive Career Theory (SCCT), so that the influential factors are still being studied $[7,22,24,27,34]$. These elements that intervene in the educational decision are also influenced by the broader culture in which we live. This is a culture in which women seem to opt for studies linked to care and education $[12,23,26,42]$. At the same time, men prefer to opt for studies in which they can build and generate [32]. This is why the female role is often associated with Health Science and Education, along with Social Services. In contrast, the male role is associated with STEM studies.

Nowadays, the technology sector is developing quickly [40]. So is the science sector, with convergence with engineering and mathematics. We live in a global society of digital and scientific advances [3]. One problem, however, is the lack of diversity in the workforce in these sectors [5]. If we ask ourselves why women are under-represented, one apparent reason is that women choose to pursue STEM-related studies at lower rates [6]. An analysis of male and female representation in these studies shows that the percentages differ from each other. It also indicates that parity between the representation groups is not achieved.

The Leaky Pipeline phenomenon exemplifies the reality studied [18]. Initially, interest in the STEM sectors is similar for men and women. However, in adolescence, they begin to lose interest. The loss of interest causes the continuity of girls in these studies to be impaired. Enrolment in higher education also drops. All this interferes with continuity in Master's and Doctorate studies, where the percentages fall [33].

Furthermore, women arriving at jobs linked to the scientific and technical sectors are less than expected. Those women who finally do get a job related to STEM hardly ever reach a higher position. Moreover, this ends up by maintaining the glass ceiling phenomenon.

For all these reasons, it is clear that the decisions made by people about their educational future and therefore also their working future are not only influenced by their self-perception, self-efficacy, interest in science, expectations of results, previous educational experiences, family and social context, personal characteristics of the person and their objectives. Social roles assumed in early life, and gender stereotypes also play a role [35, 38]. Socially, it seems to be, as previously indicated, that it is women who freely and consciously opt for studies related to the Health Sciences, education and Social Services. However, the extended cultural and social construct on gender influences the way people relate to each other and make decisions. Historically, women have been attributed to several qualities, different from the qualities of men. Men are assigned strength, courage, security, and women are assigned sensitivity, loyalty, gentleness [8].

This paper presents the pilot study carried out as part of Sonia Verdugo Castro's doctoral thesis on the gender gap in higher education in the STEM sector [13, 35-39]. To study the gender stereotypes of university students about STEM studies, an instrument has been designed for its empirical validation. The developed instrument has been applied in the pilot study. The paper aims to analyse the results of the pilot study to find out the students' opinion about STEM, mainly at the University of Salamanca, the University of Valencia and the Polytechnic University of Valencia.

The work is divided into seven sections. The first section contains the introduction, followed by the background in the second section. The third section presents the study developed. The first epigraph presents the design of the instrument, the second epigraph presents the application of the instrument for the pilot study, and the third epigraph presents the data analysis process. The fourth section presents the study sample. The fifth section presents the results of the study. The fifth section presents the conclusions. And the paper closes by referring to limitations and prospective.

\section{BACKGROUND}

Different experiences and initiatives exist. A variety of actions have been carried out by education itself and also by organizations and companies [13]. Some of these actions have been developed in the early stages of education, such as infant and primary education, others in secondary education, and others in higher education. Some actions are based on mentoring and tutoring students to promote their interest in the STEM sector [1]. It is important to convey through these actions that science, technology, engineering and mathematics are desired. They do not have to be completely technical applications without contact with human beings. These disciplines can be applied to education, health, improving lives of the human being, and for whatever creative idea one has. An example of this is Human-Computer Interaction, designed for human use and the study of phenomena. Promoting this idea is necessary to 
mitigate the myths associated with STEM. It is necessary to break with the preconceived ideas about this educational sector that they are freaky, unsocial people, etc. Breaking down these myths will help to dispel the threat of stereotyping [6].

In addition to the empirical initiatives, measurement instruments have also been constructed and applied. A review of measurement instruments was conducted before this study [37], as part of Sonia Verdugo Castro's doctoral thesis. Some of the instruments studied were the Cooperative Institutional Research Program CIRP Questionnaire - Freshman Survey [41], ROSE Questionnaire - Relevance of Science Education [31], STEM-CIS [19, 25], IRIS Q [4], and Sustainability and Gender in Engineering (SaGE) survey [2]. Many of these are tools aimed at a specific educational area, such as mathematics, engineering, technology; however, not all of them. The aspects that are frequently studied and measured are self-perception, self-efficacy and performance.

Some instruments study performance in mathematics and perceived self-efficacy in mathematics or science; however, it is not so easy to find tools designed for the study of gender stereotypes [37]. Gender stereotypes cut across all subjects and have to do with the way a person acts, how she or he perceives and interprets ideas, expressions and the world. In this case, about gender. Having a tool that addresses and measures the gender stereotypes a person has is essential. In this way one can identify what ideas one has and work on them. It is also necessary to build a tool that is not limited to a single age group or a single group of students since if it can be applied at different stages and in different contexts, the study can be extended. The comparative data allow a diagnosis of the situation to be made. Based on the diagnosis, an awareness and intervention plan can be designed. Working on stereotypes means going deeper into the roots of the problem, taking preventive and mobilising measures. If we communicate to the young population that they can study and be what they want and decide to be, while working on stereotypes, the effects of Leaky Pipeline can be mitigated. As an ultimate effect, the change in awareness helps to close the existing gender gap gradually.

\section{STUDY}

\subsection{Instrument Design}

The instrument was designed as part of the thesis carried out by Sonia Verdugo Castro at the University of Salamanca PhD Programme on Education in the Knowledge Society scope (http: $/ /$ knowledgesociety.usal.es) [14, 15].

For the design of the instrument, items from other instruments have been taken and adapted to Spanish [9, 17, 21, 29, 30]. The instrument has been applied in Spanish, although, for the work presented here, they are presented in English.

The original instrument called Opinion Questionnaire with University Students about Higher Education in Science, Technology, Engineering and Mathematics has 66 questions of which 37 are of the ordinal type and correspond to the opinion scale for university students about higher education in science, technology, engineering and mathematics. There are also five open questions. And the remaining 24 items are of a socio-demographic nature (gender, age, country of birth, nationality, area in which you live, university studies completed, University, higher course taken, motivation for choosing the studies completed, preference for your studies in the choice, whether you would go back to study, whether you have completed Vocational Training or High School, and what branch of knowledge, if you have previously been interested in the STEM sector, if you have participated in STEM initiatives, if someone from your family and/or social environment has studied STEM, if someone from your family and/or social background has been your model/referral when deciding which studies to take, or if someone from your environment has judged your decision to take your studies, the socio-economic and cultural level of the area in which you have grown up, and the level of education of your parents) The initial ordinal items have been extracted from five different sources $[9,17,21,29,30]$. To answer the items an even scale from one to four was offered, where 1 means no agreement, two means disagreement, three means agreement and four means total agreement. Table 1 presents the original items of the instrument and the descriptive items obtained after the application of the pilot study.

\subsection{Study design and data collection}

This paper presents the results of the pilot study of the instrument designed. The application of the instrument was made through a customized installation of Limesurvey, that is, online. The data collection was carried out between March and April 2020. The questionnaire was sent to the University of Salamanca, the University of Valencia and the Polytechnic University of Valencia. However, there is a $5 \%$ participation of students from other Spanish universities, given that the instrument was disseminated through the snowball technique. The questionnaire does not collect any identifying data but is entirely anonymous, and participation is voluntary. Although a total of 178 people accessed the questionnaire via Limesurvey, 115 people answered the complete questionnaire. For this reason, the 115 people who responded to the 37 ordinal questions linked to the opinion have been taken from the sample for analysis.

\subsection{Data analysis}

SPSS v.25 software was used for the pilot study data. Some of the items are formulated in positive $(25,27,36,38,59,60$ and 61$)$, others are formulated in the opposite sense to the measurement of attitude $(26,28,29,30,33,34,37,41,42,43,44,45,46,47,48$ and 49) and others are formulated to study dependency with respect to sociodemographic questions $(31,32,35,39,40,50,51,52,53,54,55,56$, 57, 58).

For the Gender Ideology, Perception and Self-Perception dimensions, low average values are expected, because the statements are posed as manifestations of stereotypes (value one means not at all in agreement, value two means in disagreement, value three means in agreement and value four means totally in agreement). However, high average values are expected for the Expectations about Science dimension, since the statements are linked to the application and importance of science in the life of the individual. For the Attitudes and Interests dimensions, on the other hand, the average values may vary according to the person responding and his or her perception.

An analysis of the study sample has been carried out. Special attention has been paid to the socio-demographic question about 
Table 1: Original instrument and descriptive items obtained after the application of the pilot study. Source: Own production based on the results obtained in SPSS.

\begin{tabular}{|c|c|c|c|c|c|c|c|}
\hline Item & Source & $\overline{\mathbf{x}}$ & $\sigma$ & developing useful software. & & 218 & 1097 \\
\hline $\begin{array}{l}\text { 25. All humans are fundamentally } \\
\text { the same, regardless of their }\end{array}$ & {$[30]$} & 3,50 & 0,949 & $\begin{array}{l}\text { employment opportunities in ICT } \\
\text { careers. }\end{array}$ & & 2,18 & 1,091 \\
\hline gender. & & & & 57. I feel comfortable working & & 3,61 & 0,757 \\
\hline $\begin{array}{l}\text { 26. If a woman decides to enter a } \\
\text { traditionally masculine field, she }\end{array}$ & & 1,61 & 0,915 & $\begin{array}{l}\text { with people of the opposite } \\
\text { gender. }\end{array}$ & & & \\
\hline will be more successful if she & & & & 58. I can enjoy a work & & 3,02 & 1,199 \\
\hline $\begin{array}{l}\text { adopts the prevailing male } \\
\text { customs and behaviors. }\end{array}$ & & & & $\begin{array}{l}\text { environment that is mostly } \\
\text { composed of men. }\end{array}$ & & & \\
\hline 27. Men and women have different & & 2,81 & 1,176 & 39. At home, boys do more & [29] & 1,83 & 1,100 \\
\hline $\begin{array}{l}\text { but equally useful ways of } \\
\text { accomplishing tasks. }\end{array}$ & & & & $\begin{array}{l}\text { practical activities with their } \\
\text { parents than girls (e.g. cars, tools, }\end{array}$ & & & \\
\hline 28. Having men and women work & & 1,34 & 0,661 & computers, etc.) & & & \\
\hline side-by-side increases the & & & & 41. Boys prefer STEM-related & & 1,86 & 0,954 \\
\hline likelihood of conflict. & & & & hobbies. & & & \\
\hline $\begin{array}{l}29 . \text { Men should not act like } \\
\text { women in the workplace. }\end{array}$ & [9] & 1,86 & 1,407 & $\begin{array}{l}\text { 42. There are more boys than girls } \\
\text { in the STEM studies as they are }\end{array}$ & & 1,94 & 1,054 \\
\hline 30. Women should not act like & & 1,88 & 1,434 & more freaks. & & & \\
\hline men in the workplace. & & & & 43. Women working in STEM & & 1,24 & 0,586 \\
\hline 31. Men who are not masculine & & 1,82 & 1,418 & areas have to be/act like men. & & & \\
\hline are good role models. & & & & 44. To have a successful career in & & 1,17 & 0,517 \\
\hline $\begin{array}{l}\text { 32. Women who are not feminine } \\
\text { are good role models. }\end{array}$ & & 1,78 & 1,407 & $\begin{array}{l}\text { STEM, you need to think and act } \\
\text { like a man. }\end{array}$ & & & \\
\hline 52. I feel restricted by the gender & & 2,13 & & 45. Girls are not as good as boys in & & 1,26 & 0,727 \\
\hline labels that people attach to me. & & & & STEM issues. & & & \\
\hline $\begin{array}{l}\text { 53. I feel restricted by the } \\
\text { expectations that people have of }\end{array}$ & & & & 46. Girls are not as interested as & & 1,53 & 0,841 \\
\hline me because of my gender. & & & & 47. STEM themes are more & & 1,48 & 0,776 \\
\hline 54. In my childhood home, I was & & & & masculine than others. & & & \\
\hline $\begin{array}{l}\text { taught that men should } \\
\text { act like men and women should } \\
\text { act like women. }\end{array}$ & & & & $\begin{array}{l}\text { 48. Girls have fewer natural } \\
\text { abilities than men for STEM } \\
\text { issues. }\end{array}$ & & 1,23 & 0,535 \\
\hline 55. In the past, I have teased or & & & 0,749 & 49. Most girls are better at other & & 1,57 & 0,860 \\
\hline $\begin{array}{l}\text { bullied someone who dressed or } \\
\text { acted like the opposite sex. }\end{array}$ & & & & things (such as letters/languages) & & & \\
\hline 56. In the past, I have been teased & & 1,62 & 0,942 & $\begin{array}{l}\text { and choose studies in which they } \\
\text { are better. }\end{array}$ & & & \\
\hline $\begin{array}{l}\text { or bullied for acting like the } \\
\text { opposite sex. }\end{array}$ & & & & $\begin{array}{l}\text { 50. Careers in STEM are not } \\
\text { associated with the traditional }\end{array}$ & & 2,64 & 1,036 \\
\hline 33. University studies are more & {$[21]$} & 1,16 & 0,410 & role of women. & & & \\
\hline $\begin{array}{l}\text { important for men than for } \\
\text { women. }\end{array}$ & & & & $\begin{array}{l}\text { 51. University studies in STEM are } \\
\text { generally more attractive to boys. }\end{array}$ & & 2,28 & 1,039 \\
\hline $\begin{array}{l}\text { 34. Women must sacrifice their } \\
\text { careers to support their }\end{array}$ & & 1,20 & 0,533 & $\begin{array}{l}59 . \text { Science is helpful in my } \\
\text { everyday life. }\end{array}$ & [17] & 3,19 & 0,999 \\
\hline children/family. & & & & 60. Learning science has made me & & 2,83 & 1,184 \\
\hline 35. The well-being of the family is & & 2,63 & 1,095 & more critical in general. & & & \\
\hline $\begin{array}{l}\text { more important than the rewards } \\
\text { of work. }\end{array}$ & & & & $\begin{array}{l}\text { 61. Science and technologies will } \\
\text { provide greater opportunities for }\end{array}$ & & 3,39 & 0,980 \\
\hline 36. Women have the same & & 3,31 & 1,012 & future generations. & & & \\
\hline
\end{tabular}

37. In the ICT field, a man's

$1,17 \quad 0,529$

performance will be better than a woman's.

38. Women are capable of

developing useful software.

40. Women and men have equal

57. I feel comfortable working

gender.

0,529

3

3,66

0,887

the same, regardless of their

26. If a woman decides to enter a

58. I can enjoy a work

composed of men.

9. At home, boys do more

41. Boys prefer STEM-related

, 954

42. There are more boys than girls

the STEM studies as they are

STEM, you need to think and act

like a man.

masculine than others.

48. Girls have fewer natural

issues.

49. Most girls are better at other

things (such as letters/languages)

50. Careers in STEM are not

role of women.

51. University studies in STEM are generally more attractive to boys. 9. Science is helpful in my everyday life.

. Learning science has made me 61. Science and technologies will provide greater opportunities for uture generations. 
the main reason for choosing the studies undertaken. Special consideration was also given to the influence of the environment and the family, both in favour and against their studies. Moreover, they asked whether any person in their environment or family had studied STEM. Also, a descriptive analysis of the responses to the ordinal items was made as a first diagnosis of the situation. Finally, non-parametric tests have been applied to test hypotheses.

A limitation of the study is the high percentage of women participants compared to the low percentage of men. Not having a gender-balanced sample (male, female, another gender not indicated) makes it difficult to find differences in responses by gender.

\section{STUDY SAMPLE}

Of the 115 people, 106 are women, and 8 are men. The age of the subjects ranges from 18 to 34 years, with the mid-range being from 18 to 24 years. $95.65 \%$ of the participants were born in Spain. There is a homogeneous distribution concerning the area in which they live, $39.13 \%$ live in urban areas, $32.27 \%$ live in intermediate areas, and $28.70 \%$ live in rural areas.

About the university degree they are studying, $64.91 \%$ study Pedagogy, 18.42\% study Industrial Design Engineering, 9.65\% study Speech Therapy, 3.51\% study Social Education, $1.75 \%$ study Pharmacy, $0.88 \%$ Nursing, $0.88 \%$ Chemistry. Regarding the university where the participants are carrying out their studies, $53.91 \%$ are students from the University of Salamanca, $22.61 \%$ from the University of Valencia (Estudi General), $18.26 \%$ from the Polytechnic University of Valencia, $1.74 \%$ from the University of Alcalá, and $0.87 \%$ from the Santa Teresa de Jesús de Ávila Catholic University, the University of Granada, the University of Seville and the Rovira i Virgili University. $60.87 \%$ have chosen their studies for the attraction to them, $57.39 \%$ have decided to take their degree to improve the quality of life of society, $40 \%$ to find a job, $39.13 \%$ to give back and help society, $28.70 \%$ for cultural enrichment, $23.48 \%$ for the possibility of working on projects, $19.13 \%$ for the possibility of working in a team, $17.39 \%$ to meet interesting people, $8.70 \%$ to set up their own business, $5.22 \%$ for social recognition, $4.35 \%$ because of family willingness, $3.48 \%$ because of high salaries, $2.61 \%$ because they consider it an option to travel, $2.61 \%$ because other friends have studied it and $1.74 \%$ because the educational centre is close to their home. Other options that have stood out in all cases are social assistance, comorbidity with other studies, not entering the chosen career as a first option, the mark obtained in selectivity, discarding and $1.74 \%$ for vocation.

The $97.39 \%$ of the sample has previously studied high school; forty-six people have studied the Social Sciences modality, 26 people the Health Sciences modality, 20 people the Scientific-Technological modality, 17 people the Humanities modality and three people the Arts modality. $9.57 \%$ of the participants have previously studied professional training; eight people in the branch of knowledge of Social and Legal Sciences, two people in the branch of Arts and Humanities and one person in the branch of Engineering and Architecture.

On the other hand, $42.61 \%$ of the sample, before their university studies, have felt interested in higher studies related to science, technology, engineering and mathematics. However, only $28.35 \%$ have participated in any initiative or activity related to the sector.

\section{ANALYSIS AND RESULTS}

In the case of the items that have been formulated in positive, all the items have been scored high (values 3 and 4, in agreement and totally in agreement). In relation to the highest averages, the order has been as follows, by items: 38, 25, 61, 36, 59, 60 and 27. For items which have been formulated in reverse, all have an average of between 1 and 2 points. As the items are formulated in reverse, in this case, 1 and 2 points imply the meanings fully agreed and agreed. The items dependent on the modulating variables $(31,32$, $35,39,40,50,51,52,53,54,55,56,57,58)$ are modulated according to the person who responds to them. To identify the modulating variables, it can be concluded that the average for items 31,32 , $39,40,51,52,53,54,55$ and 56 points to values between 1 and 2 . Meanwhile, for items 35, 50, 57 and 58, the average points to values between 3 and 4 .

Also, different hypothesis contrasts have been applied for the five dimensions (Gender Ideology, Perception and Self-Perception, Expectations about Science, Attitudes and Interests) and the sociodemographic variables of the instrument. The five dimensions have been calculated and defined from the process of Exploratory Factor Analysis. From the process of contrasting hypotheses, it can be checked if, for the study sample, significant differences are found in the answers given by the participants to the different questions that make up the dimensions, according to their socio-demographic data. The socio-demographic variables set out in the study are linked to the social and family context of the person, and to previous experiences lived at a training level.

Hypothesis testing has been based on non-parametric methods. For two independent groups, the Mann Whitney U-test has been applied, and for three or more independent groups, the KruskalWallis test has been used.

In total, 18 significant differences have been found by sociodemographic variables, with respect to the five dimensions. Table 2 is presented where the socio-demographic variables by which significant differences in the dimensions and the $\mathrm{p}$-value are found are briefly exposed.

\section{DISCUSSION AND CONCLUSIONS}

According to the results, four significant differences have been found for the Gender Ideology dimension according to sociodemographic variables: about the area in which the student lives (rural, intermediate, urban), the motivation for choosing their 'Possibility of working on projects' studies, the branch of studies they are studying at University (for the pilot study two categories have been created: Social and Health Sciences, and Engineering and Chemistry), and with the condition of having felt interested in higher STEM studies throughout their pre-University training. The scores assigned by the participants on the peer scale on the stereotypes assigned to gender ideology are low for those living in rural, intermediate and urban environments. However, for those who live in a rural environment, the score is higher, approaching a value of 2 (average 1.86). For those who have chosen their studies because of the possibility of working in projects, the scores for the items are favourable, as the average response value is 1.55. As regards the scores assigned in the answers according to the branch of studies 
Table 2: Significant differences obtained from the contrasts of non-parametric hypotheses of Mann Whitney U-test and Kruskal-Wallis Source: Own production based on the results obtained in SPSS.

\begin{tabular}{l} 
Results of significant difference \\
hypotheses \\
\hline Gender Ideology scale: is \\
the opinion about different \\
genders, that is, the capacities, \\
abilities and behaviour of \\
people according to their \\
gender. \\
Perception and \\
Self-Perception scale: is the \\
view one has about the \\
development of people \\
according to their gender in \\
certain situations. And \\
self-perception is the view one \\
has about the development of \\
oneself in such situations \\
according to one's gender.
\end{tabular}

Attitude scale: respond to beliefs and values about how people should act in accordance with their gender. Science Expectations scale: are the perceived opportunities about the potential of scientific and technical disciplines.

Interest scale: are the predisposition and attraction to scientific and technical disciplines according to gender.

Zone - sig. 0.027

Motivation to choose studies

(option 'Possibility to work on projects') - sig. 0.035

Branch of study - sig. 0.032

Previous interest in STEM sig. 0.035

The socio-economic and cultural level - sig. 0.016 Motivation to choose studies (option 'It's an option to travel') - sig. 0.010

Preference in the choice of studies - sig. 0.048

Family and environment that questioned your decision ('One teacher' option) - sig. 0.047

Parent/guardian education level - sig. 0.044

Zone - sig. 0.020

Course - sig. 0.004

Motivation to choose studies (option 'Possibility to work on projects') - sig. 0.005 Branch of study - sig. 0.001 Having completed vocational training sig. 0.034 Previous interest in STEM sig. 0.000

Age - sig. 0.039

The environment has studied STEM ('Mother' option) - sig. 0.033

Family and environment model/ reference for studies (option 'Other relative (uncle, cousin, grandfather, etc.) - sig. 0.041

taken (Social and Health Sciences, and Engineering and Chemistry), although the average scores are low, which is favourable, the average for those participants in Engineering and Chemistry is higher, with an average of 1.74 compared to 1.52 for participants in Social and Health Sciences. Furthermore, although the scores in the answers are also low concerning the condition of having felt interested in higher STEM studies, before the University, for those who have not thought it, the scores are higher with an average of 1.77 compared to 1.60 for those who have felt interested.

In addition, for the dimension of Perception and Self-Perception, four significant differences were found according to sociodemographic variables: about the socio-economic and cultural level to which they consider that the area where they were born and raised belongs, the motivation for choosing their studies of 'It's an option to travel', the position of preference that their studies had at the time of deciding (first choice, second choice or another choice), and the condition that a male teacher would question their decision to take their studies. About the socio-economic and cultural level, the scores assigned are favourable, given that they are between 1 and 2. However, the highest average is for those people who consider the area in which they were born and grew up to be of a low-medium level (average of 2.04), followed by the average of the medium level (average of 1.80), and finally, the medium-high level (average of 1.63). The average score assigned to the answers for those people who have chosen their studies because they are an option to travel is 2.51, which represents a slightly unfavourable trend. In terms of the position of preference for choosing their studies, the average scores are favourable, although those who had chosen their studies as a second option or more have an average of 1.89 compared to 1.72 for those who decided their studies as a first option. And for those people who were questioned by a male teacher about their choice of studies, the average is 2.07.

Furthermore, for the Science Expectations dimension, seven significant differences were found according to socio-demographic variables: about the area in which the student lives (rural, intermediate, urban), the higher academic year in which they have enrolled, the motivation for choosing their 'Possibility of working on projects' studies, the branch of studies they are studying at the University (two categories have been created for the pilot study: Social and Health Sciences, and Engineering and Chemistry), having studied Vocational Training, the condition of having felt interested in higher STEM studies throughout their pre-university training, and with the age group to which the student belongs (18-19, 20-21, 2234 ). Concerning the area in which the participants live, in all three categories (rural, intermediate, urban) the values are favourable, as they are positive. Although in the metropolitan area the expectations about science are higher with an average of 3.5 compared to the intermediate site with an average of 3.38 and, finally, the rural area has the lowest value of the three groups' average of 3.15. Concerning the expectations about science and the higher course in which the person has enrolled, the average score is favourable in the different categories, showing the most optimistic value in the first course as the highest in which the person has enrolled, followed by the first course, the second course with higher scores is fourth. This coincides with the usual beginning and end of a university degree (in the case of four- year degrees). Those people who have chosen their studies for the motivation of the possibility of working on projects have high expectations, with an average of 3.63 .

On the other hand, and paradoxically, those who have higher average values concerning expectations about science are those who study Social and Health Sciences (average of 3.71) compared to those who study Engineering and Chemistry (average of 3. 28). 
Continuing with the formation studied, those who have not previously studied Vocational Training have more favourable average scores (3.40) than those who have previously studied Vocational Training (3.03). As far as the presence or not of previous interest in higher STEM studies is concerned, there is a clear relationship, with the highest score being given to those who have previously shown interest (average of 3.58) compared to those who have not yet shown interest (3.20). Finally, about the age of the participants, those who are in the first years of the university degree (18 and 19 years old) have higher average scores (3.54) than participants who are 20 years old or older (3.26).

Moreover, for the Attitude dimension, a significant difference was found about the educational level of the parent/legal guardian. Concerning beliefs about appropriate attitudes for men and women, the academic level of the father/guardian has an influence, since those participants whose father has no education present average value of 4.00 , while those participants whose father has primary education present average value of 2.61 , those whose father has secondary education present average value of 2.42 and those whose father has higher education show average value of 2.05. Finally, for those participants who do not have a father, the average response value is 1.56 .

Finally, for the Interest dimension, two significant differences have been found about the environment of the student who has studied STEM, specifically the mother and the family and environment that has been a model/reference for the studies taken, specifically a male relative from the extended family, such as an uncle, cousin, grandfather, etc. Those whose mother has completed higher STEM studies have an average value on the scale of 3.17 . And, on the other hand, those people who have had a male relative from the extended family as a model/referral for their studies have an average value on the scale of 2.65 . Both values tend to agree with the statements.

As can be seen from the results, both the perceived socioeconomic and cultural level of the area/n which they were born and raised and the area in which they live (rural, intermediate, urban) are part of the context that influences the perception of reality. Another fundamental contextual factor in opinion and stereotypes is the family and social environment. Both for and against the decision made by the student, the family and close environment, including teachers, are influential in the student's opinion and perception. In this way, in a family and social context, they can be taken as a role model and reference, or as a handicap in the process of choice. Another family element that presents significant differences with respect to opinion is the educational level of the father.

However, the elements that influence students' opinion are not only the contextual, family and social ones. Previous educational experience and the level of education attained also influence opinion. Previous vocational training, the branch of study chosen, prior interest in the STEM sector, the highest course achieved, and even the preferred position in which the studies taken were listed are all factors related to the student's opinion of higher STEM studies.

Finally, the student's age and motivation for choosing a course of study are also related to the opinion of STEM studies.

In conclusion, it can be admitted that for the sample used in the pilot study, the context in which they have lived and are living, previous educational experiences, the personal motivation and the social and family environment are factors to be considered, as also assumed by other authors [12, 23, 26, 32, 42], some of them linked to the Social Cognitive Career Theory (SCCT) [20], such as [7, 22, 24, 27, 34].

Finally, the results of the pilot study reveal that the study sample is not particularly marked by gender stereotypes about gender equality in STEM. To those specific items regarding women's abilities to perform scientific and technical activities, the sample responds favourably. For example, this is seen in the favourable response to "Women are capable of developing useful software" and "Men and women have different but equally useful ways of accomplishing tasks". Also, the sample is receptive to learning about science and applying it in their lives. This can be seen in their responses to items 59, 60 and 61 .

On the other hand, the idea that women must give up their studies and careers to take care their families and children is rejected. The idea that men are more interested in university studies than women is also rejected. This can be seen in the responses to items such as "University studies are more important for men than for women" and "Women must sacrifice their careers to support their children/family". The idea that women's success in the STEM sector depends on acting like men is also rejected. This is seen in response to items such as "Women working in STEM areas have to be/act like men". At the same time, the sample is sensitized to the difficulties women face in the STEM sector, with responses to items such as "Women and men have equal employment opportunities in ICT careers". Another optimistic point of the results is that there are no alarming data on bad experiences due to gender. In the responses to items such as "I feel restricted by the gender labels that people attach to me", "I feel restricted by the expectations that people have of me because of my gender", "In my childhood home, I was taught that men should act like men and women should act like women" and "In the past, I have teased or bullied someone who dressed or acted like the opposite sex", the response trend is between 1 and 2, which represents low values.

This favourable and optimistic data may be because $93 \%$ of the sample are women, and $70 \%$ of the sample was taken from Education-related degrees. This profile may fit with people who are aware of the invisible barriers that some groups suffer when accessing socially male-dominated contexts. It is favourable to obtain these results, as it shows that positive actions are being carried out from the educational and social spheres to raise collective awareness. However, we cannot forget that part of society which is not yet aware, and which needs to be recruited in order to promote equal representation in the STEM sector. The study of gender stereotypes is a crucial part of the field. This will enable us to work on a personal perspective and the promotion of equal opportunities in accessing and completing STEM studies.

\section{LIMITATIONS AND FUTURE PROSPECTS}

The main limitation found in the study was that $93 \%$ of the sample were women, and over $70 \%$ were in education. This has created a homogeneous profile. There has indeed been a diversity of responses to the items, and it has been possible to visualize the trend of stereotyped thoughts and behaviours in the sample. However, the overall assessment is positive, with favourable results. It would 
have been interesting to have a heterogeneous profile in which to find a greater diversity of responses in order to discover which dimensions need to be worked on most.

Another limitation is that the results can only be extrapolated to the sample used in the pilot study.

Since this work is part of a more extensive study, the next step is to apply the instrument to a broader context with a larger sample.

\section{ACKNOWLEDGMENTS}

This research work has been carried out within the University of Salamanca PhD Programme on Education in the Knowledge Society scope (http://knowledgesociety.usal.es) $[14,15]$, and this research was supported by the Spanish Ministerio de Ciencia, Innovación y Universidades under a FPU fellowship (FPU017/01252).

\section{REFERENCES}

[1] K. Atkins, B.M. Dougan, M.S. Dromgold-Sermen, et al. 2020. "Looking at Myself in the Future": how mentoring shapes scientific identity for STEM students from underrepresented groups. International fournal of STEM Education.7, 1. DOI: https://doi.org/10.1186/s40594-020-00242-3.

[2] J. Blizzard, L. Klotz, G. Potvin, et al. 2015. Using survey questions to identify and learn more about those who exhibit design thinking traits. Design Studies. 38 92-110. DOI: https://doi.org/10.1016/j.destud.2015.02.002.

[3] N. Broughton, and Social Market Foundation. 2013. In the balance: the STEM human capital crunch.

[4] G. Cerinsek, T. Hribar, N. Glodez, et al. 2013. Which are my Future Career Priorities and What Influenced my Choice of Studying Science, Technology, Engineering or Mathematics? Some Insights on Educational Choice-Case of Slovenia. International fournal of Science Education. 35, 17, 2999-3025. DOI https://doi.org/10.1080/09500693.2012.681813.

[5] N. Codiroli. 2017. Who studies STEM subjects at A level and degree in England? An investigation into the intersections between students' family background, gender and ethnicity in determining choice. British Educational Research fournal.43, 3, 528-553. DOI: https://doi.org/10.1002/berj.3270.

[6] C. Corbett and C. Hill. 2015. Solving the equation: the variables for women's success in engineering and computing. AAUW.

[7] M. Cupani, A.E. Azpilicueta and V. Sialle. 2017. Evaluación de un modelo socialcognitivo de la elección de la carrera desde la tipología de Holland en estudiantes de la escuela secundaria. Revista Española de Orientación y Psicopedagogía.28, 3, $18-24$.

[8] C. Delgado, A. Iraegui, L. Marquina, et al.2007. Patrones de masculinidad y feminidad asociados al ciclo de la violencia de género. Revista de Investigación Educativa. 25, 1, 187-217.

[9] S.G. Duncan, G. Aguilar, C.G. Jensen, et al. 2019. Survey of Heteronormative Attitudes and Tolerance Toward Gender Non-conformity in Mountain West Undergraduate Students. Frontiers in Psychology. 10.DOI: https://doi.org/10.3389/ fpsyg.2019.00793.

[10] European Institute for Gender Equality: 2020. https://eige.europa.eu/.Accessed: 2020-09-07.

[11] Eurostat. Tu clave para las estadísticas europeas: 2020. https://ec.europa.eu/ eurostat/web/education-and-training/data/database.Accessed: 2020-09-07.

[12] J.G. Figueroa and T. Hernández. 2019. Hombres en profesiones de cuidado tradicionalmente feminizadas. Papeles de población. 25, 100, 121-151.

[13] A. García-Holgado, S. Verdugo-Castro, C. González, et al. 2020. European Proposals to Work in the Gender Gap in STEM: A Systematic Analysis. Revista Iberoamericana de Tecnologias del Aprendizaje (IEEE RITA).15, 3, 215-224. DOI https://doi.org/10.1109/RITA.2020.3008138.

[14] F.J. García-Peñalvo. Engineering contributions to a Knowledge Society multicultural perspective. IEEE Revista Iberoamericana de Tecnologías del Aprendizaje (IEEE RITA). 10, 1, 17-18.

[15] F.J. García-Peñalvo. 2014. Formación en la sociedad del conocimiento, un programa de doctorado con una perspectiva interdisciplinar. Education in the Knowledge Society.15, 1, 4-9.

[16] C.E. George, E.L. Castro and B. Rincon. 2019. Investigating the origins of STEM intervention programs: an isomorphic analysis. Studies in Higher Education.44, 9 , 1645-1661. DOI: https://doi.org/10.1080/03075079.2018.1458224.

[17] A. Godwin. 2014. Understanding Female Engineering Enrollment: Explaining Choice with Critical Engineering Agency. All Dissertations.

[18] M. Goulden, K. Frasch and M.A. Mason. 2009. Patching America's Leaky Pipeline in the Sciences. 52.

[19] M.W. Kier, M.R. Blanchard, J.W. Osborne, et al. 2014. The Development of the STEM Career Interest Survey (STEM-CIS). Research in Science Education.44, 3,
461-481. DOI: https://doi.org/10.1007/s11165-013-9389-3.

[20] R.W. Lent, S.D. Brown and G. Hackett. 1994. Toward a Unifying Social Cognitive Theory of Career and Academic Interest, Choice, and Performance. Fournal of Vocational Behavior.45, 1, 79-122. DOI: https://doi.org/10.1006/jvbe.1994.1027.

[21] D.M. López. 2013. El género como factor determinante al escoger una carrera profesional en sistemas de información. Universidad del Turabo. Escuela de Negocios y Empresarismo.

[22] L.A. Medrano and P.E. Flores. 2017. La problemática del ingreso a la Universidad desde una perspectiva de la teoría de la agencia social: aportes de la Teoría Social Cognitiva. Revista Argentina de Educación Superior. 15, 11-35.

[23] A. Morales. 2010. Género, mujeres, trabajo social y sección femenina. Historia de una profesión feminizada y con vocación feminista. Universidad de Granada.

[24] J.V. Peña, M.I. Caro and M.C. Rodríguez. 2015. La teoría cognitivo social de desarrollo de la carrera: evidencias al modelo con una muestra de estudiantes universitarios de la rama científica. Bordón. Revista de pedagogía. 67, 3, 103-122.

[25] K. Peterman, R. Kermish-Allen, G. Knezek, et al. 2016. Measuring Student Career Interest within the Context of Technology-Enhanced STEM Projects: A CrossProject Comparison Study Based on the Career Interest Questionnaire. Fournal of Science Education and Technology. 25, 6, 833-845. DOI: https://doi.org/10.1007/ s10956-016-9617-5.

[26] S.C. Pinzón, M.V. Aponte and M.L. Useche. 2017. ¿Sexismo en enfermería? Una mirada desde la perspectiva de género a roles feminizados como el cuidado. Prospectiva: Revista de Trabajo Social e Intervención Social. 123-146.

[27] M.C. Rodríguez, J.V. Peña and M.I. Caro. 2015. Validación de la teoría cognitivo social de desarrollo de la carrera con una muestra de estudiantes de ingeniería. Educación XX1: Revista de la Facultad de Educación. 18, 2, 257-276.

[28] P.N. Rojas. 2019. La promoción profesional de las mujeres en el mercado de trabajo español. Propuestas para reducir la segregación horizontal y vertical. Femeris: Revista Multidisciplinar de Estudios de Género. 4, 2, 70-104.

[29] A.E. Rossi and M. Barajas. 2015. Elección de estudios CTIM y desequilibrios de género. Enseñanza de las ciencias.0059-0076. DOI: https://doi.org/10.5565/rev/ ensciencias. 1481.

[30] S. Banchefsky and B. Park 2018. Negative Gender Ideologies and Gender-Science Stereotypes Are More Pervasive in Male-Dominated Academic Disciplines. Social Sciences.7, 2, 27. DOI: https://doi.org/10.3390/socsci7020027.

[31] L.J. Sax. 2009. Women Graduates of Single-sex and Coeducational High Schools, Differences in Their Characteristics and the Transition to College. Sudikoff Family Institute for Education \& New Media, UCLA Graduate School of Education \& Information Studies.

[32] G. Stoet and D.C. Geary. 2018. The Gender-Equality Paradox in Science, Technology, Engineering, and Mathematics Education. Psychological Science.29, 4, 581-593. DOI: https://doi.org/10.1177/0956797617741719.

[33] K. Szelényi, K. Bresonis and M.M. Mars. 2016. Who Am I versus Who Can I Become?: Exploring Women's Science Identities in STEM Ph.D. Programs. The Review of Higher Education.40, 1, 1-31. DOI: https://doi.org/10.1353/rhe.2016.0036.

[34] I.M. Vázquez and A. Blanco. 2019. Factores sociocognitivos asociados a la elección de estudios científico-matemáticos. Un análisis diferencial por sexo y curso en la Educación Secundaria. Revista de investigación educativa, RIE.37, 1, 269-286.

[35] S. Verdugo-Castro, A. García-Holgado and M.C. Sánchez-Gómez. 2019. Age influence in gender stereotypes related to Internet use in young people: a case study. Proceedings of the 7th International Conference on Technological Ecosystems for Enhancing Multiculturality (TEEM 2019) (León, Spain, October 16-18, 2019).M.Á. Conde-González et al., eds. ACM. 223-231.

[36] S. Verdugo-Castro, A. García-Holgado and M.C. Sánchez-Gómez. In press. Análisis e intervención sobre la brecha de género en los ámbitos educativos STEM. Estudios interdisciplinares de género. Tirant Lo Blanch.

[37] S. Verdugo-Castro, A. García-Holgado and M.C. Sánchez-Gómez. 2019. Analysis of instruments focused on gender gap in STEM education. Proceedings of the 7th International Conference on Technological Ecosystems for Enhancing Multiculturality (TEEM 2019) (León, Spain, October 16-18, 2019).M.Á. Conde-González et al., eds. ACM. 999-1006.

[38] S. Verdugo-Castro, A. García-Holgado and M.C. Sánchez-Gómez. 2019. Percepción de los estereotipos de género asociados al uso de Internet en estudiantes de pedagogía. Aprendizaje, Innovación y Cooperación como impulsores del cambio metodológico. Actas del V Congreso Internacional sobre Aprendizaje, Innovación y Competitividad. CINAIC 2019 (9-11 de octubre de 2019, Zaragoza, España).M.L. SeinEchaluce Lacleta et al., eds. Servicio de Publicaciones Universidad de Zaragoza. 629-634.

[39] S. Verdugo-Castro, M.C. Sánchez-Gómez, A. García-Holgado, et al. 2019. Revisión y estudio cualitativo sobre la brecha de género en el ámbito educativo STEM por la influencia de los estereotipos de género. Atas - Investigação Qualitativa em Ciências Sociais/Investigación Cualitativa en Ciencias Sociales.A.P. Costa et al., eds. 381-386.

[40] M. Winterbotham. 2014. The UK Commission's Employer Skills Survey 2013: UK Results. London, UK Commission.200.

[41] HERI. 2020. Encuesta de estudiantes de primer año del CIRP - HERI.

[42] 2012. La feminización de las profesiones. Sistema: revista de ciencias sociales.228, $81-96$. 